\title{
ON THE ACTION OF NITROUS ANHYDRIDE (NI'TROGEN TRIOXIDE), DISSOLVED IN CARBON DISULPHIDE, UPON DIFFERENT ORGANIC COMPOUNDS.
}

\author{
By L. H. Frienburg and John A. Mandel. \\ (First Paper.)
}

The action of free nitrous anhydride upon organic bodies capable of reacting with it, varies greatly and is generally productive of changes more profound than simple substitution. But if under the influence of this action substitution products are formed, these belong to the nitroso, or to the isonitroso, compounds. 'The formation of nitro products, however, in this manner is exceptional.

Thus, primary amines of the fatty series are changed into the corresponding hydroxyl derivatives, while secondary amines yield nitroso amines and tertiary amines are not acted upon. Amido bodies of the aromatic serjes are transformed into diazo compounds, wbile the imide group gives rise to nitroso derivatives.

Some investigators have found the action of nitrous anhydride to be oxydizing* upon hydrocarbons and substituting in the highest degree upon phenol $\nmid$ forming picric acid with the latter. An easily accessible reference for the general literature of this action of nitrous anhydride upon organic bodies is Beilstein's Handbuch der Organischen Chemie, 1886. (Vol. I., pp. 110 and 111.)

It has seemed to us that in lessening the violence of this reaction by the diluting influence of some third substance of indifferent behavior new results might be obtained. Other chemists have attempted in a general way to control the method and make it more readily available. Thus Stenhouse \& Groves I used a solution of nitrous anhydride in conc. sulphuric acid to prepare nitrosophenol and Weselsky $\&$ used common ether as a dilutent

* A. R. Leeds, J. Anı. Chem. Soc., 2 (1880), 17.

† A. R. Leeds, J. Am. Chem. Soc., 2 (1880), 422.

$\ddagger$ Ann. Chem. (Liebig), 188, 354.

$\S$ Ber. chem. Ges., 8, 98. 
for $\mathrm{N}_{2} \mathrm{O}_{3}$ in the preparation of diazophenol nitrate and mononitro phenols. About fifteen years ago, one of 11 , experimenting then on carbon disulphide, found this latter to be an excellent. solvent for gases of very different character, and at that time * tried the action of nitrogen dioxide dissolved in $\mathrm{C}_{2} S_{2}$ upon different bodies. The results not being of special interest, al thongh they showed the possibility of obtaining substitution as well as addition productst in this way, the use of a solution of nitrous anhydride in carbon disulphide suggested itself as the nextstep. 'The results here submitted are to be regarded as preliminary only; the authors intend to pursue the investigation and to apply the reaction above mentioned in many different cases.

First as to the preparation of nitrous anhydride. Arsenious. oxide $\left(\mathrm{As}_{2} \mathrm{O}_{3}\right)$ in rery fine powder is treated with c. I. nitric acid of $1.42 \mathrm{sp}$. gr. in a capacions flask provided with delivery tube and thistle tube with safety bulbs. The gas is slowly generated and passed through several $L$ tubes filled with spirals and flat pieces of test lead so as to free the gas from all nitric acid. The receiver, from the start, is surrounded with a mixture of ice and salt, and the green liquid obtained is redistilled once from this recuiver into a similar one which is put into the freezing mixture while the first is immersed in tepid water. Thus a rear, ark blue fluid is obtained and only traces of liquid uitric acid remain in the original receiver.

The $\mathrm{N}_{2} \mathrm{O}_{3}$ thus prepared is then gently poured into carbon disulphide, previously purified and freed from dissolved sulphur, by shaking it at intervals, for a day or more, with mereury. The mixture of $\mathrm{CS}_{2}$ and $\mathrm{N}_{2} \mathrm{O}_{3}$ must also stand in the freezing mixture. This is the nitrous anlyydride solution as we invariably use it. The body to be acted upon is likewise dissolved in $C_{2}$ and kept in the cooling mixture. The nitrous anhydride solution is added to the solution to be treated very slowiy, best in drops. 'The heat of the reaction is thus kept down as much as possible and the spontancous evaporation of some of the CK, assists in the reduction of temperature. The organic substances which have thus

* Ber. d. chem. Ges., 8, 1616 .

†J. Am. Chens. Soc., 4, 252, 1882. 
far been submitted to the action of nitrous anhydride by the above methods are benzol, phenol and diphenylamine.

Benzol and Nitrous Anhydride.-The products under these conditions are exclusively mono-nitrobenzol and para-dinitrobenzol; the latter, which is formed in larger quantity, occurs in flat crystals, which after the first recrystallization melt at exactly $89^{\circ}$ C. Under the conditions it could not be ascertained whether nitrous oxide was amongst the products of reaction; but if this be assumed, as it may be, according to the investigations of Iseeds*, we may write as the equation for this reaction :

$\mathrm{C}_{6} \mathrm{H}_{6}+2 \mathrm{~N}_{2} \mathrm{O}_{3}=$ para $\mathrm{C}_{6} \mathrm{H}_{4}\left(\mathrm{NO}_{2}\right)_{2}+\mathrm{H}_{2} \mathrm{O}+\mathrm{N}_{2} \mathrm{O}$, while for the formation of mononitrobenzol, which is obtained at the same time, the equation would be :

$2 \mathrm{C}_{6} \mathrm{H}_{6}+2 \mathrm{~N}_{2} \mathrm{O}_{3}=2 \mathrm{C}_{6} \mathrm{H}_{5} \mathrm{NO}_{2}+\mathrm{H}_{2} \mathrm{O}+\mathrm{N}_{2} \mathrm{O}$. According to this equation two molecules of benzol must take part in the reaction, and, since an excess of nitrous anhydride was used, the predominance of the dinitro compound is explained.

Leeds (loc. cit.) working with undiluted nitrous anhydride obtained, in addition to mononitrobenzol, oxalic acid with water of crystallization, and the formation of this latter makes it more than likely that our reactions took place in the manner above suggested.

Phenol and Nitrous Anhydride.-In this case the results corresponded in part to those of Weselsky (loc. cit.) who used common ether as a diluting agent and obtained orthomono- and paramononitrophenol, but Weselsky obtained at the same time diazophenol nitrate, which precipitated; of this we did not obtain a trace, while nitrosophenol formed one third of the products in our experiment. Very small quantities of higher nitro compounds, which formed also, may, for the present, be neglected.

The greater part of the volatile orthonitrophenol remains dissolved in the carbon disulphide, while none of the paranitrophenol is dissolved. This solution is easily decanted from the underlying liquid which contains some ortho, and all of the para and nitroso compounds. The separation is effected by distillation in a

* J. Am. Chem. Soc. $2(1880), 426$. 
current of steam and the para compound is thus left in the retort, but portions of it, though not volatile, as well as some of the non-volatile nitroso compound are carried over into the distillate, which renders purification necessary. The distillate is shaken with ether. From this solution, which was not yellow but strongly dichroic between purple and green, olive green crystals of orthonitrophenol were obtained. These, when redissolved in water and distilled in a small fraction tube at gentle heat, yielded a crop of beautiful, straw yellow erystals of orthonitrophenol which inelted at $45^{\circ} \mathrm{C}$.

The remaining liquid in the fraction mbe showed Liebermann's nitroso reaction and decomposed to black, powdery bodies as impure nitrosophenol does. The paranitrophenol was crystallized from its solution and, after frequent recrystallizations, was obtained in crystals an inch in length, showing the exact melting point of $114^{\circ} \mathrm{C}$. The reaction offers us also two well defined equations. For the formation of the two isomeric mononitrophenols :

$$
2 \mathrm{C}_{6} \mathrm{H}_{5} \mathrm{OH}+2 \mathrm{~N}_{2} \mathrm{O}_{3}=2 \mathrm{C}_{6} \mathrm{H}_{4} \quad \mathrm{NO}_{2} \mathrm{OH}+\mathrm{H}_{2} \mathrm{O}+\mathrm{N}_{2} \mathrm{O} ;
$$

and for the nitrosophenol,

$$
2 \mathrm{C}_{6} \mathrm{H}_{5} \mathrm{OH}+\mathrm{N}_{2} \mathrm{O}_{3}=\mathrm{H}_{2} \mathrm{O}+2 \mathrm{C}_{6} \quad \mathrm{H}_{4} \mathrm{NO} . \mathrm{OH} \text {; }
$$

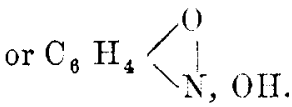

Diphenylanine and Nitrous Anhydricle--This reaction was effected in three different ways:

I.--The diphenylamine was dissolved in absolute alcohol and the solution of nitrous anhydride in $\mathrm{CS}_{2}$ was added. The alcohol not having been sufficient to keep all the carbon disulphide dissolved, enough was added to obtain a uniform solution.

II.-The diphenylamine as well as the nitrous anhydride were separately dissolved in $\mathrm{CS}_{2}$ and the solutions were then mixed.

III.-Experiment II. was repeated with diphenylamine dissolved in $\mathrm{CS}_{2}$ in which an equivalent amount of sulphur had previously been dissulved.

1. 'This experiment furnished after twelve hours an abundant quantity of light wax yellow needles a quarter of an inch long, 
which had in crystallizing adhered to another compound forming small, brick-red, warty masses. The separation of these two compounds was based upon the lesser solubility of the red portions in ether and their greater solubility in benzol. Very small quantities of ether were added to the bulk of the mixture of crystals after they had been very thoroughly pressed between filter paper. Thus solutions were obtained which on crystallizing. gave an abundance of the yellow and but few of the red crystals. Repeated, insufficient exhaustion of these with ether, gave us finally, perfectly pure, light amber colored, thick prisms, which were paramononitrodiphenylarnine, melting at $133^{\circ} \mathrm{C}$.

The red portions, also crystallized from ether (benzol was abandoned as a solvent, because the substance, as long as it was not quite pure, separated too slowly from this solvent) were subjected to sublimation and yielded a beatiful, scarlet red sublimate of very long needles, melting at $210^{\circ} \mathrm{C}$., thus indicating that the compound was orthodinitrodiphenylamine. In one particular portion of the ethereal solution of the para compound, a large quantity of thick, hard, garnet-red crystals which appeared to be rhombic octahedra were obtained. Crushed in a mortar these crystals gave an orange-yellow powder, melting at $215^{\circ} \mathrm{C}$, properties characteristic of paradinitrodiphenylamine.

II. and III. 'The carbon disulphide solution of diphenylamine, to which equivalent amounts of sulphur had been added, when mixed with solution of $\mathrm{N}_{2} \mathrm{O}_{3}$ in $\mathrm{CS}_{2}$, yielded, on rapid evaporation, principally crystals of paramononitrodiphenylamine, melting at $133^{\circ} \mathrm{C}$. When, before evaporation, absolute alcohol was added, the total amount of sulphur was precipitated. The sulphur had been added in order to see whether this element, which reacts so easily with diphenylamine, could not, simultaneously with the nitrogroup, be incorporated into it.

In experiment I, the mother liquors were allowed to crystallize to the very last drop and thus, successively, mixtures of crystals were obtained which appeared progressively darker. The formation of nitroso compounds was suggested by the dark greenish coloration and the perceptibly acid odor of the latter portions.

We have made a number of varied qualitative experiments upon 
other compounds of the aromatic series and intend soon to describe the action of $\mathrm{N}_{2} \mathrm{O}_{3}$ in $\mathrm{CS}_{2}$ solution upon the aldehydes, acids and amido derivatives of the same.

College of the City of New York, Janumy $3 d, 1890$.

\section{ON THE ALLEGED STERILIZATION OF RIVER WATER BI MINE WA'TER.}

BY A. A. BRExEMas.

During an epidemic of typhoid fever which oceurred in the city of Wilkesbarre, Pa., in the Summer of 1889 , questions arose as to the purity of the different sources of water supply upon which the city depended, and the writer was called upon to make an examination of the waters in question. 'The water of the Susquehanna River is one of these and is the only one concerned in the present discussion. The history of the epidemic and its causes is not at present to the purpose.

It was found that the river water was preferred by the public and by local physicians to water from adjacent mountain streams in spite of the fact that it receives above Wilkesbirre the sewage of nearly 100,000 people in the course of ten miles, the city of Scranton, which discharges its sewage into the Susquehanna through a tributary, the lackawanna, and of Pittston, which is directly on the river, being the principal sources of contamination.

This peculiar faith in the purity of a river so open to defilement is traceable in part to the general indifference to filth that is known to be largely diluted, but much more to the influence of certain articles published in the local papers with the stamp of official commendation and the authority of scientific or quasi scientific opinion.

It was believed by the people of Wilkesbarre that the river water was peculiarly free from possibility of transmitting infectious diseases because of the considerable quantities of mine water 